\title{
STRATEGIC MODELLING OF PASSENGER TRANSPORT IN WATERWAYS: THE CASE OF THE MAGDALENA RIVER
}

\author{
Laura BERRIO, Víctor CANTILLO*, Julian ARELLANA \\ Dept of Civil and Environmental Engineering, North University, Barranquilla, Colombia
}

Received 12 September 2016; revised 21 September 2017, 26 March 2018; accepted 5 May 2018

\begin{abstract}
In some Colombian regions, inland waterways play a relevant role in passenger mobility. However, many characteristics of their operation, required for planning purposes, are unknown. Existing data and studies are few and undetailed. In this context, collecting data and developing supply and demand models will make it possible to not only improving the knowledge of inland waterway transport in the country, but also the planning of the system. In this investigation, a survey instrument was designed and employed to collect data about passenger flows in seven ports on the Magdalena River, the most important river in Colombia. The collected information was used to specify and estimate strategic supply and demand models. Models based on the classic four-step model and alternative synthetic models were estimated and compared. The proposed models contribute to better understanding of the behaviour of inland waterway transport passengers. They were used to evaluate policies aimed at improving the users' level of service and to encourage the utilisation of this mode of transport. Results show that accessibility variables and variables related to zone size define trip generation and distribution. In addition, it was found that inland waterway users in Colombia are highly cost sensitive.
\end{abstract}

Keywords: inland waterways, passenger transport, Magdalena River, strategic modelling, intermodal network, accessibility.

\section{Introduction}

Inland waterways are recognised as an efficient, safe, and environmentally friendly mode of transport (Márquez, Cantillo 2013). For this reason, policies have been proposed to promote this mode of transport (Ivančić et al. 2013; Mihic et al. 2011). However, for passenger mobility, the competition between the waterways versus road or rail transport is complex (Nam, Win 2014; Tournaye et al. 2010).

Despite the fact that it has accessibility limitations, inland waterway transport is a desirable alternative to road transport, especially in Latin America. In particular, Colombia has several navigable rivers that are used for transporting passengers and freight (Vega et al. 2019).

Even though this transport mode for moving passengers has limited accessibility and few improvements over time compared to road or air transport, it is still the best alternative in some regions where road accessibility is challenging. There is extensive research on freight transport by inland waterways, but not so much on passenger transport, which means that the singularities of the operation of this mode of transport are unknown. Being more specific, the variables that are influential in the dynamics of the functioning of the inland waterway transport passenger, which consciously allow decision-making, have not been evaluated in detail. Therefore, there is a gap in the knowledge about the impact that is generated by this mode of transport and its relationship with other modes of transport, which is why it is important to study this issue.

The main waterway in Colombia is the Magdalena River, which is also the subject of study in this paper. Today, the institution that administers the passenger transport service at the main ports of the Magdalena River only records the number of travellers (arrivals and departures) at each port, but there is no additional information available to allow further analysis. Therefore, policies and decisions are frequently made based on empirical knowledge. For planning purposes, it is necessary to have more detailed data to develop suitable supply and demand models.

Very few studies on passenger transport by inland waterways have been reported in the literature. For instance, Dobbins and Langsdon (2013) reported the use of data from automatic identification systems to generate inland waterway trip information, allowing the information to

${ }^{\star}$ Corresponding author. E-mail: victor.cantillo@uninorte.edu.co 
be used to make risk analyses. Recently, environmental concerns and perceptions about comfort and safety have been introduced in the studies using hybrid mode, choicelatent variable modelling (Kim et al. 2012; Márquez et al. 2014). Camay et al. (2012) made an economic analysis of the improvement of economic conditions after the implementation of a transport plan, using the New York ferry services as a study case.

Because of the limited background available, in many cases, decision makers do have not enough information to create policies to improve the competitiveness of the mode of transport. Trying to define an approximation to calculate the supply and demand in river transport is a complex challenge. Nevertheless, experience has been gathered from studies of other modes of transport, which allows for the presumption of the criteria necessary for the collection of data about vehicles and passengers. Such pursuits will become extremely useful for analysis and modelling (Ortúzar, Willumsen 2011).

The purpose of this research is to understand the behaviour of inland waterway transport passengers using demand and supply models, obtaining valuable information and indicators that could be used to create policies to improve the users' level of service. For this reason, an evaluation of the impact of policies related to the subject is included in the research. Furthermore, this study is a basis for advanced analysis in passenger transport by inland waterway and even intermodal transport.

This paper presents a theoretical description and a case study application of two modelling frameworks for this modality. The first proposed approach is an adaptation of the classic four-step model. Classical transport modelling considers the use of diverse methodologies from external variables to assess the number of trips between Origins and Destinations (O-D). The second approach refers to alternative synthetic (direct demand) models - particularly useful when information is limited. They are an alternative approach to classic models. Synthetic modelling employs socioeconomic and trip characteristic variables to predict transport flows.

The proposed models contribute to the better understanding of the behaviour of inland waterway transport passengers. All of these variables were applied to passenger mobility on the Magdalena River. Relevant methodological contributions include the use of the accessibility variable in generation models, the use of mixed stated and Revealed Preference (RP) data for modal split models, and the estimation of relevant indicators, such as the subjective value of time and elasticities to variables in the analysed context.

This paper continues with a description of the case under study and the methodology used to collect the necessary data for modelling the supply and demand of inland waterway transport in Colombia. Later, the development of the four-step classic transport model and some alternative approaches are presented. Finally, results will be presented, allowing for identification of the characteristics of this particular mode of transport before drawing the relevant conclusions to the study.

\section{Data}

This study of inland waterway transport of passengers is based on the case of the Magdalena River. It is possible to transport passengers on the river all year long. About $90 \%$ of total trips on the river depart or arrive from seven major ports and from north to south, they are Calamar, Magangué, El Banco, Gamarra, Barrancabermeja, Puerto Berrío, and Puerto Boyacá/Puerto Salgar.

Each port authority has records of the number of passengers moved monthly. This information allows for the evaluation of the role and importance of inland waterways in each zone (Figure 1). The port of Magangué usually moves the largest number of passengers, followed by Barrancabermeja. In contrast, the ports of Gamarra and Puerto Boyacá have the smallest mobility; in these locations, most of the trips are across the river, not travelling up or down it. Figure 2 shows the number of passengers that use each port monthly.

The historical data collected by the ports authorities is not enough to develop strategic transport modelling. In order to close this gap, this research project, which was funded by the Colombian Ministry of Transport, included the design and application of three instruments for gathering relevant data for planning purposes. The first instrument contained traffic counts; the second one kept track of trip O-D; and the third gathered Stated Preference (SP) in the form of a survey.

The traffic counts data registered a detailed inventory of incoming and outgoing vessels from the port. Meanwhile, the O-D survey contained information about the $\mathrm{O}-\mathrm{D}$ of the vehicles, the hour at which the vehicles were dispatched, arrival times (in the case of an incoming vessel), the number of outgoing passengers, and the number of available seats.

The SP survey was designed in pursuit of building models of modal choice and finding out passenger pref-

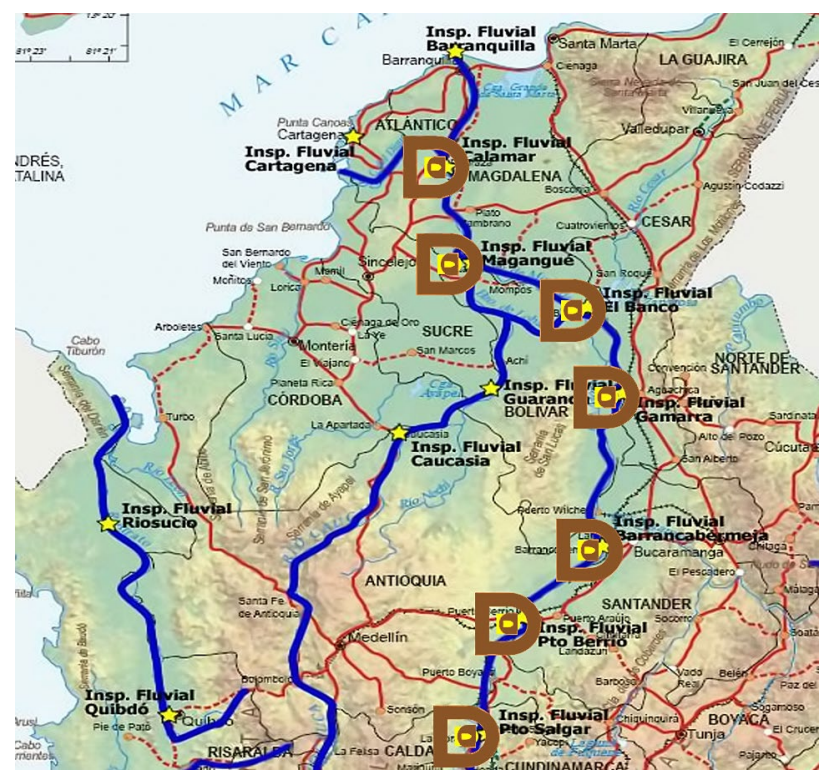

Figure 1. Study zone 


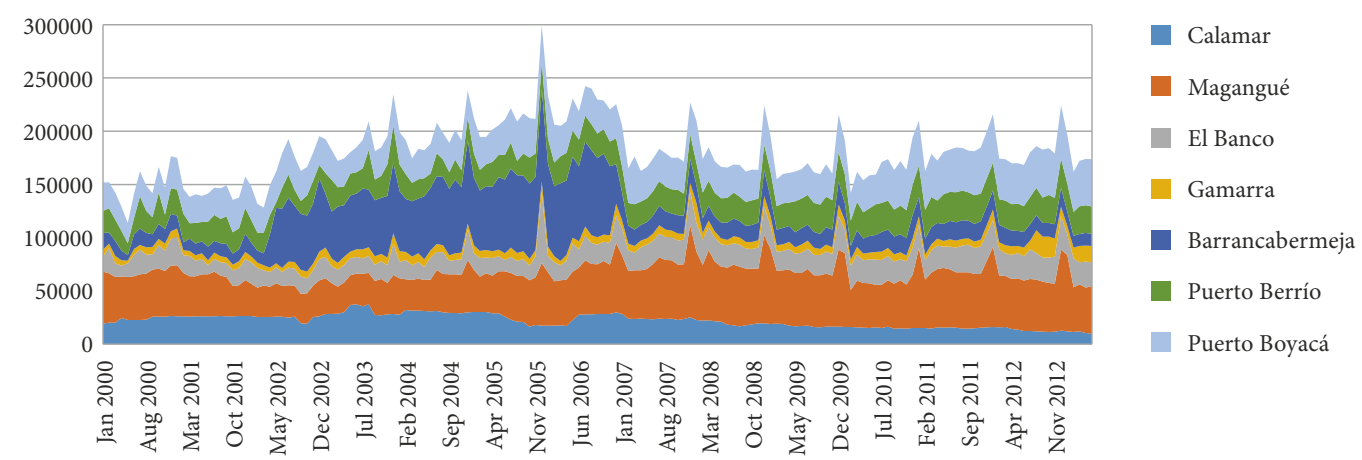

Figure 2. Number of passengers at ports per month

erences regarding the existing travel options, including other alternatives. The interviewee had to choose between transport by waterways, rail, and bus in nine different hypothetical, but realistic, scenarios with variables such as value of fare, travel time and waiting time. It is important to mention that at the moment, transport by rail or bus were not existing alternatives for all travellers.

The second instrument was a RP survey. It was used to obtain data about the O-D of passenger trips, trip chaining, socioeconomic characteristics of the passenger (age, gender, occupation, income), and trip characteristics (purpose, cost, time, travel companion, transfers, frequency). According to the obtained data, the number of arrivals and departures in each port is shown in Table 1, confirming that Magangué is the most visited port on the Magdalena River.

Table 1. Number of personal trips at each port per day

\begin{tabular}{|l|c|c|}
\hline \multicolumn{1}{|c|}{ Zone name } & Entrance & Departure \\
\hline Calamar & 159 & 164 \\
\hline Magangué & 1180 & 1243 \\
\hline El Banco & 642 & 627 \\
\hline Gamarra & 62 & 80 \\
\hline Barrancabermeja & 332 & 289 \\
\hline Puerto Boyacá & 440 & 658 \\
\hline Puerto Berrío & 120 & 99 \\
\hline
\end{tabular}

For modelling purposes, it was necessary to implement an appropriate zoning design. The political-administrative division of the country involves 32 departments. Departments are formed by groupings of municipalities, which are the basic territorial units. As a criterion for zoning, areas near the river were created out of existing municipalities. Further, away from the river, several municipalities or even departments were aggregated according to proximity and the departments were grouped to create areas. Subsequently, internal and external areas were defined, which should facilitate the choice of representative zones that should be used in the modelling. In total, 40 internal areas associated with riverside municipalities were defined, as well as 56 external areas. The criterion in question was developed by taking into account the way in which census data was available as well as the political and administrative division of the country. With the aim of presenting the results, the areas were regrouped in eight bigger macro-zones: seven in correspondence with the influence zone of each port evaluated, and one external that grouped the rest of the zones. The zone system was agreed to by the Ministry of Transport of the Colombia. Figure 3 illustrates both the detailed zoning, and the aggregation into macro-zones.

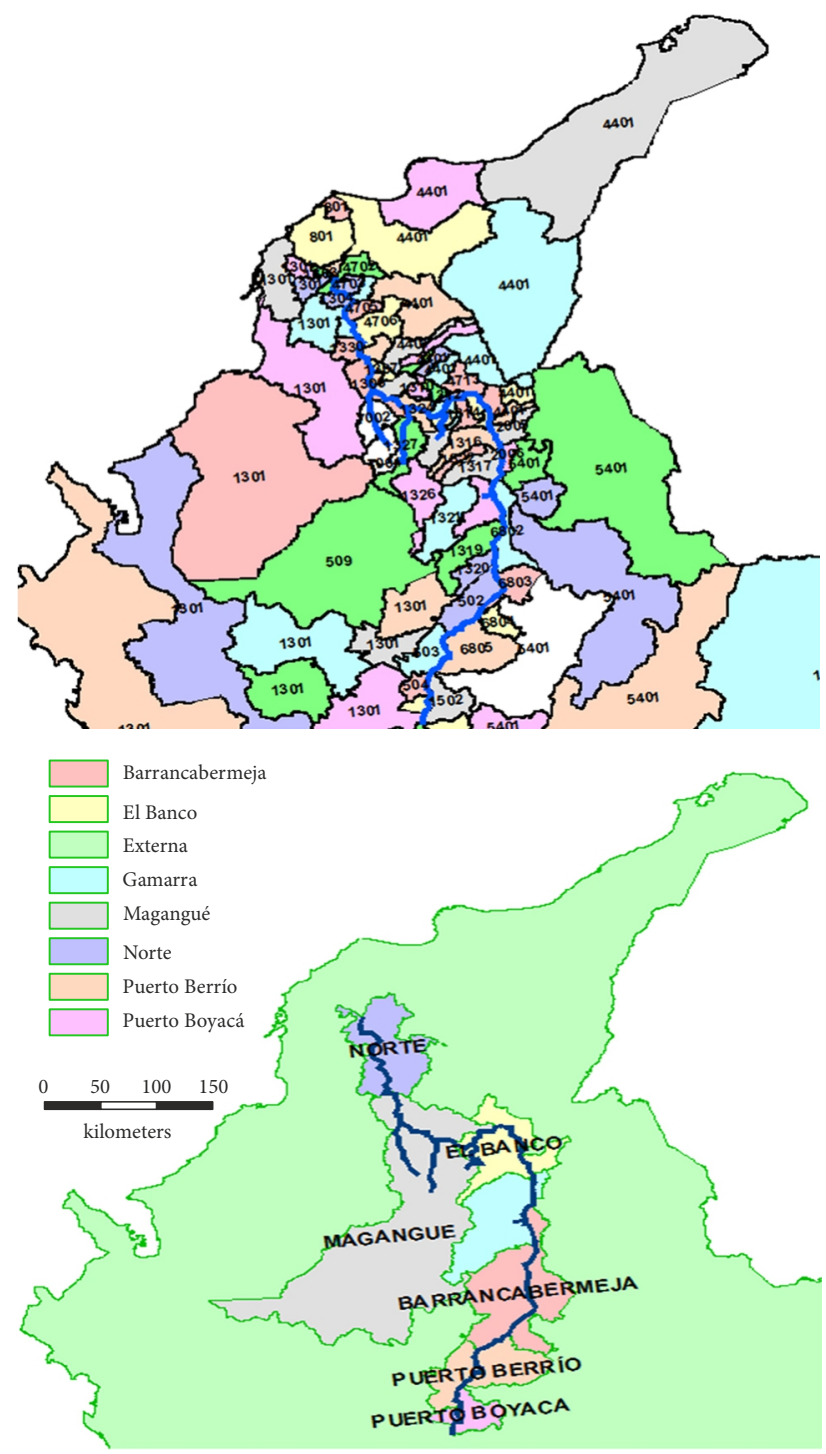

Figure 3. Detailed and aggregated zoning in macro-zones 


\section{Demand transport models}

The classic approach for strategic transport modelling involves dividing the supply and demand analysis into four steps: trip generation and attraction modelling, trip distribution modelling, modal split and, finally, trip assignment modelling Ortúzar and Willumsen (2011). First, a treatment of the data was carried out, establishing the zoning, and grouping the information in each area. Such information was used to develop each step in the methodology.

In addition to classic modelling, in this paper two alternative models were used. The first is the direct demand model, which allows the generation and travel distribution to be found directly. The second model contemplates the destination choice separately by using the theory of discrete choices.

In all the cases, the models simulate the demand based on specific variables, which are also good indicators that could be used to create policies that would have a major impact and allow for better understanding of the behaviour of inland waterway transport potential passengers, which is an essential basis for new research.

\subsection{Trip generation and attraction modelling}

The goal of this step to obtain the generated and attracted trips in each zone. There are several modelling techniques, which can be used to estimate those trips. In the particular case of this study, Multiple Linear Regression (MLR) models at the zonal level were used (Ortúzar, Willumsen 2011). The criterion variable for trip generation is the number of trips that come out of each zone, and for trip attraction during a single day the number of trips that arrive at each zone is used, using the same predictor variables to explain the number of trips in both cases.

The information obtained from the RP surveys was used to calibrate the parameters to represent attracted and generated trips in the 40 areas defined as internal zones. The independent variables in the model were:

- Population $P_{i}$ : the population in the zone, in millions of inhabitants according to the National Department of Statistics of the Colombia;

- River inspection $I_{i}$ : a binary variable, which takes the value of one (1) if there is an inspection (formal port authority) in the area, and zero (0) otherwise;

- Accessibility $A_{i}$ : this is a way to represent the accessibility of each of the zones, from the generalised costs of travel. Initially, the parameter $\beta$ of the distribution model must be derived. It is calculated using Equation (1). This kind of measure for accessibility can be integrated better into the models based on activities, including modelling for tours (Dong et al. 2006).

$A C C_{i}=\frac{1}{\beta} \cdot \ln \left(\sum_{j=1}^{n} \exp \left(-\beta \cdot c_{i j}\right)\right)$,

where: $\beta$ is the parameter of the distribution model; $C_{i j}$ is the generalised cost of travelling between zones $i$ and $j$.
It is relevant to clarify that other variables such as health indicators (e.g. number of beds in hospitals), economic indicators (e.g. local gross domestic product), and educational indicators (e.g. number of students) were considered at early stages to explain trip generation and attraction, as well as variables relating to the economic activities and socioeconomic variables of passengers. However, they were not included in the selected models since they show a strong correlation with population, which is an easy variable to estimate and more appropriate for use in this kind of modelling.

It was determined that the best scheme for modelling generation and attraction is the one that highlights the interaction between the population and the existence of river inspection in the area. This scheme is shown in Equation (2):

$$
T_{i}=\alpha_{1} \cdot P_{i}+\alpha_{2} \cdot P_{i} \cdot I_{i}+\alpha_{3} \cdot A C C_{i},
$$

where: $P_{i}, I_{i}$ and $A C C_{i}$ are the population, river inspection and accessibility variables, respectively, as defined before; meanwhile, $\alpha_{1}, \alpha_{2}$ and $\alpha_{3}$ are the parameters of the model to be estimated.

The constant term was set to zero to avoid a size effect. The parameter values were determined and the statistical $t$ of "student" was evaluated for each variable (values are in parentheses below the corresponding parameter). Thus, the daily trips generated by zone $i$ are given by Equation (3):

$$
\begin{gathered}
O_{i}=1.02 \cdot P_{i}+4.32 \cdot\left(P_{i} \cdot I_{i}\right)+1.62 \cdot A C C_{i} \\
(4.36) \quad(11.33)
\end{gathered}
$$

adjusted $r^{2}=0.89$.

Meanwhile, the estimated attraction model follows the function shown in Equation (4):

$$
\begin{gathered}
D_{j}=1.21 \cdot P_{j}+3.49 \cdot\left(P_{j} \cdot I_{j}\right)+1.65 \cdot A C C_{j} \\
(4.77) \quad(8.42)
\end{gathered}
$$

adjusted $r^{2}=0.89$.

The similarity of the models is noticeable, which can be explained to a large extent by the symmetry of the trips. It is important to highlight that trip generation and attraction are strongly linked, so it is natural that these models share explicative variables. Figures 4 and 5 show the trips generated and attracted by macro-zone, respectively.

\subsection{Trip distribution modelling}

After the estimation of the total generated and attracted trips, the number of trips between each O-D pair is estimated in the second step. For the trips between internal areas, a gravity model involving the generalised cost of travel between each pair of zones was used (Cascetta et al. 2007). Equation 5 shows the structure of the function that was applied for each $\mathrm{O}-\mathrm{D}$ pair:

$$
T_{i j}=A_{i} \cdot O_{i} \cdot B_{j} \cdot D_{j} \cdot f\left(C_{i j}\right),
$$

where: $A_{i}$ and $B_{i}$ are parameters for calibration, one for the number of trips started in $i$ and one for the trip ending in $j$; 


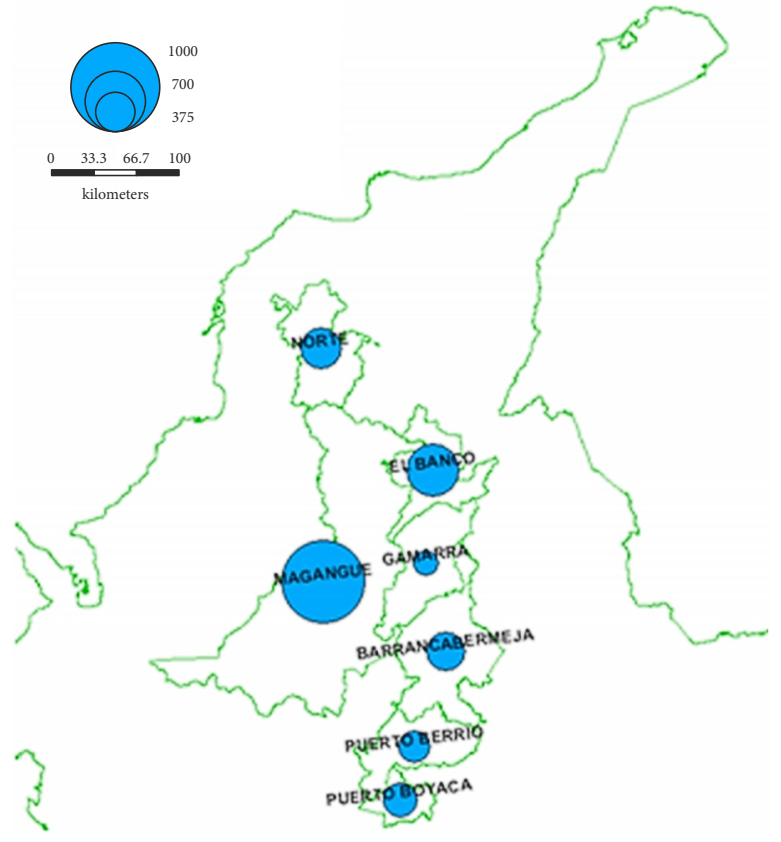

Figure 4. Generated trips by macro-zone

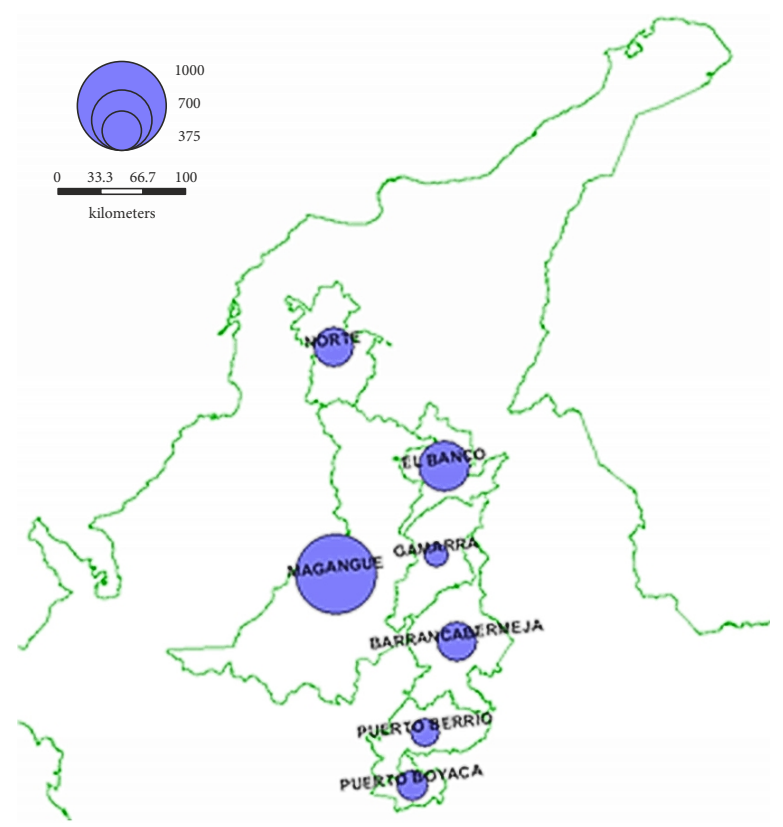

Figure 5. Attracted trips by macro-zone

$f\left(C_{i j}\right)$ is a cost function that includes the monetary cost and the associated cost of travel time in thousands of Colombian pesos (COP). In this case, the lowest generalised cost found is 1.4 thousand COP ( 1 USD $=2000$ COP at the time of the survey) for a trip between two zones without fare, so it only consists of travel time. The highest generalised cost is 1206.8 thousand COP, which is the cost for a trip that needs several transfers and several fare payments.

An exponential function was chosen after finding out that it was the one, which best described the behaviour of the distribution of travel costs. This function is presented in Equation (6), with $\beta$ being the parameter to be cali- brated and which sets the impact of the generalised travel cost between each O-D pair on trip distribution according to total trips generated and attracted by each zone, since it is the value of elasticity per generalised cost unit:

$$
f\left(C_{i j}\right)=\exp \left(-\beta \cdot C_{i j}\right) \text {. }
$$

Model calibration requires establishing a zoning system, defining the modelling periods, having an $\mathrm{O}-\mathrm{D}$ matrix of a base year, and having a matrix of cost and travel time. The matrix was doubly bounded through the Furness Method (Ortúzar, Willumsen 2011). There are several methods to calibrate the parameter $\beta$; in this investigation the method proposed by Hyman (1969) was used, which is a robust and efficient way of proceeding.

In order to calibrate the distribution model, the expanded O-D matrix of internal zones, which was obtained from the data gathered through the PR survey, was used as basic information. The matrix of generalised cost gave way to the calibration of $\beta$, achieving a value of 0.048 . This means that the generalised cost affects the distribution of the number of trips between each origin (O) destination (D) O-D pair according to the total number of trips generated in $\mathrm{O}$ and attracted to $\mathrm{D}$, but in a smaller proportion considering the low multiplication factor.

Thus, having calculated the projection of the generalised cost for future years, the number of generated and attracted trips, and the calibrated parameter $\beta$, it is possible to estimate the number of trips between each $\mathrm{O}-\mathrm{D}$ pair.

The price elasticity of the number of trips generated between each pair of zones is defined by the mathematical expression: $-\beta \cdot C_{i j}$, which means that the variation of the number of trips between each pair of zones is directly affected by the magnitude of the costs for the users. Growthfactor modelling was used for trips with an $\mathrm{O}$ or $\mathrm{D}$ in external zones (Ortúzar, Willumsen 2011). This method is easier to estimate and does not fit in the current modelled distribution.

\subsection{Modal split}

The third step, modal split, was established by discrete choice models, which are based on random utility theory (Domencich, McFadden 1975). According to this theory, each individual in the choice process has a set of available alternatives that are described by measurable and comparable attributes (e.g. costs, travel time). Alternative $A_{j}$ has an associated utility $U_{j q}$ for individual $q$, described by Equation (7):

$$
U_{j q}=V_{j q}+\varepsilon_{j q}
$$

where: $V_{j q}$ is a systematic component of the utility that can be measured. This component is based on a vector of measurable attributes, specific to each alternative and to characteristics of the individual. Frequently, when the systematic utility is expressed as linear in the parameters, then $V_{j q}=\theta \cdot X_{j q}$, where $\theta$ is a set of parameters to be estimated; $\varepsilon_{j q}$ is a random error that follows a Gumbel distribution, which reflects uncertainty and particular 
preferences besides measuring and observing errors by the modeller. Assuming this error distribution, the classic Multinomial Logit Model (MNL) is obtained (Ortúzar, Willumsen 2011). For this model, the probability that the individual $q$ chooses the alternative $A_{i}, P_{i q}$, is given by Equation (8), where it is normalised (commonly $\lambda=1$ ) by the inability to be estimated independently from the set of parameters $\theta$ :

$$
P_{i q}=\frac{\exp \left(\lambda \cdot V_{i q}\right)}{\sum_{A_{j} \in A_{q}} \exp \left(\lambda \cdot V_{i q}\right)} .
$$

One of the applications of discrete choice models is the estimation of willingness to pay for an attribute, as markets do not provide such information in a direct way. In particular, it is of interest to determine the subjective value of time, which can be estimated as the marginal rate of substitution between income and time. From the calculation of elasticity of demand, it is possible to calculate how the demand varies regarding changes in attributes.

Most of the Magdalena River transport users are captive, since there are no other alternative ways to perform the trip. Above all, trips are made in nearby areas, travelling for less than $150 \mathrm{~km}$ most of the time. However, in some sectors, particularly near Barrancabermeja, inland waterway transport is in competition with rail and road services (bus).

A mode choice model was made using the information collected in the Barrancabermeja zone, where passenger transport by road, rail, and inland waterway exists. RP and SP surveys were applied by interviewing users of those modes in transport terminals and stations.

The RP surveys asked about users' socioeconomic characteristics (age, occupation, gender, etc.) and information on their current trip (origin, destination, mode, fare, travel time, transfers, and service indicators). SP surveys assessed nine hypothetical scenarios, where the user could choose between passenger transport services by road, rail, or inland waterway for a specific trip. Each scenario took into account the variation of comparable characteristics for each mode: cost [thousands COP], travel time [min], and headway between vehicles [min]. Altogether, $207 \mathrm{RP}$ and SP surveys were applied, of which 67 surveys were given to rail passenger transport users, 56 to bus users, and 84 to inland waterway transport users.

The mode choice model was estimated by combining RP and SP data (Ben-Akiva, Morikawa 1990). The methodology calculated a scale coefficient for the RP data $\lambda^{R P}$. Meanwhile, the scale factor for the SP data was set to one. The calibrated results of the MNL are displayed in Table 2.

With this model, the value of time calculated is $81.8 \mathrm{COP} / \mathrm{min}$ in rail transport, $55.8 \mathrm{COP} / \mathrm{min}$ in bus services and $159.4 \mathrm{COP} / \mathrm{min}$ for inland waterway transport. It is evident that individuals have the highest willingness to pay for reducing travel time when using inland water- ways when compared with the other two alternatives.

Furthermore, the elasticities were calculated for each variable and mode, and the results are shown in Table 3. It can be seen that users of every mode are more sensitive to cost than to other variables, especially inland waterway users. In contrast, users are less sensitive to service frequencies (i.e. headways), especially for buses.

Table 2. Mode choice model

\begin{tabular}{|c|c|c|}
\hline Parameter & Value & $t$-value \\
\hline $\operatorname{ASC~}^{*}$ & -3.95 & -2.48 \\
\hline $\mathrm{ASC} \mathrm{B}^{*}$ & -5.8 & -3.65 \\
\hline ASC IW ${ }^{*}$ & \multicolumn{2}{|c|}{ fixed } \\
\hline Cost $(\mathrm{A}, \mathrm{B}, \mathrm{IW})^{\star *}$ & -0.418 & -4.00 \\
\hline Time (A) & -0.034 & -4.49 \\
\hline Time (B) & -0.023 & -4.13 \\
\hline Time (IW) & -0.066 & -4.78 \\
\hline Headway (A, B, C) & -0.013 & -4.38 \\
\hline$\lambda^{R P}$ & 0.591 & -2.90 \\
\hline$N$ & \multicolumn{2}{|c|}{2070} \\
\hline Log-likelihood & \multicolumn{2}{|c|}{-1535.8} \\
\hline$\rho^{2}$ & \multicolumn{2}{|c|}{0.12} \\
\hline
\end{tabular}

Notes: ${ }^{*} \mathrm{~A}$ - railways, B - bus, IW - inland waterways; ${ }^{* *} 1 \mathrm{USD}=$ 2000 COP when the survey was applied.

Table 3. Direct elasticities obtained from mode choice model

\begin{tabular}{|l|c|c|c|}
\hline \multicolumn{1}{|c|}{ Elasticity } & Rail & Bus & Inland waterways \\
\hline Cost & -0.595 & -0.699 & -0.990 \\
\hline Time & -0.507 & -0.282 & -0.760 \\
\hline Headway & -0.370 & -0.194 & -0.263 \\
\hline
\end{tabular}

\subsection{An alternative approach: direct demand model}

An alternative approach to the classic transport demand model is to develop a model directly subsuming several of its steps. The direct demand models are mathematical adjustment (synthetic) models, closely related to econometric models, which may provide a generalised overview of demand. A positive alternative is developing an approach that incorporates all the levels of sequential modelling, which may significantly reduce errors coming from the progress of levels modelling (Ortúzar, Willumsen 2011).

The models of direct demand relate the passenger volume between each pair of zones with certain characteristics, those being the structure of the multiplicative equation and associated socioeconomic variables, and the conducted travel. In the literature, it is common to implement the size of the population of the origin $P_{i}$ and the destination $P_{j}$, as well as the basic characteristics of the modelled trips between pairs of zones. In general terms, the cost of travel fares and the associated time are included, because of their correspondence to intrinsic variables 
of the activity being conducted. Nonetheless, a function of generalised cost can be implemented that allows for the evaluation of the travel cost as a total (Wardman et al. 2007), as indicated in Equation (9):

$$
T_{i j}=\phi\left(P_{i} \cdot P_{j}\right)^{\rho_{1}} \cdot\left(C_{i j}\right)^{\rho_{2}} \cdot \prod_{k} \gamma_{k}^{\rho_{k}},
$$

where: $C_{i j}$ is the function of generalised cost; $\phi$ and the $\rho$ 's are parameters to be calibrated; parameters $\rho_{1}, \rho_{2}$ and $\rho_{k}$ are the elasticities of demand with respect to population, the generalised costs, and the additional explicative variables $\gamma_{k}$, respectively.

In this paper, the cost function is adapted to monetary units, involving the concept of generalised cost of travel, and contemplating the value of time obtained in the modal split model as show in Equation (10):

$$
C_{i j}=C_{V i j}+\tau_{t v} \cdot T_{V i j},
$$

where: $T_{V}$ is the travel time; $\tau_{t v}$ is the value of travel time; $C_{V}$ is the travel fare.

Regarding the calibration of the direct demand model, an expanded trips matrix created with the information obtained through the RP survey was used. Information about population was obtained from official sources. Besides population and the generalised cost function, the proposed model includes variables frequency and number of transfers as follows:

$$
V_{i j}=\phi\left(P_{i} \cdot P_{j}\right)^{\rho_{1}} \cdot\left(C_{i j}\right)^{\rho_{2}} \cdot \text { freq } q_{i j}^{\rho_{3}} \cdot \exp \left(\rho_{4} \cdot \text { transf }_{i j}\right),
$$

where: variable freq represents service frequency in river modes - the number of dispatched vehicles per day; the trips for river access were not taken into account because the available modes varied, so this is assumed sufficient for avoiding delays in waiting time (dispatches per day); meanwhile, transf is the number of transfers made during the trip; to incorporate the number of transfers in the model, an exponential transformation was made in order to avoid the zero cases.

To make the process of model calibration simpler, the equation was linearized, applying the natural logarithm function to both equation sides. By using least squares, the model was estimated, resulting in the direct demand model presented in Table $4\left(R^{2}=0.396\right)$. As the parameters of explicative variables are their respective elasticities, it may be noted that the generalised cost is the most relevant attribute in the model.

Table 4. Direct demand model

\begin{tabular}{|l|c|c|c|}
\hline \multicolumn{2}{|c|}{ Variable } & Parameter & $t$-value \\
\hline Constant & $\phi$ & 6.72 & 7.38 \\
\hline$P_{i} \cdot P_{j}$ & $\rho_{1}$ & 0.16 & 4.18 \\
\hline$C_{i j}$ & $\rho_{2}$ & -0.74 & -8.39 \\
\hline freq & $\rho_{3}$ & 0.19 & 2.46 \\
\hline transf & $\rho_{4}$ & -0.38 & -4.12 \\
\hline
\end{tabular}

\section{Supply model: trip assignment}

The transport supply is modelled by assigning flows to the different navigable links of the network. For this purpose, the basic premise was the assumption of a rational traveller who chose the route, which offered the least perceived cost, represented by the specific fare and the monetary value of the travel time. Once zoning was defined, details about nodes or points of access, egress, or transfers, and the navigable ways that compound the network were provided. In addition, the function of representative (generalised) costs and other network characteristics should be defined.

The river transport services on the Magdalena River are provided by two types of equipment: Chalupas and Motocanoas. Chalupas are boats with a capacity of twenty to thirty passengers, while Motocanoas are larger boats, with a capacity of thirty to forty passengers.

Several options for traffic assignment are available. Different assignment algorithms include the shortest path, the optimal strategies, and the stochastic user equilibrium method (Ortúzar, Willumsen 2011). The stochastic user equilibrium method was chosen, because it allows a better approximation of user behaviour. This method assigns the flow between a specific O-D to the best available paths considering the generalised cost of them. In the case of this research, the parameters of the stochastic model were calibrated using the applied O-D surveys. It was also based on the strategic model for Colombia proposed by Cantillo et al. (2014). This assignment method is iterative and begins with the pursuit of the shortest route from the origin to the destination (Sheffi 1985), alternating its components randomly with the error terms. The individuals select an option based on its attributes, such as travel time, waiting time, rates, and transfer penalties. Then, the model assigns the flows to the most attractive routes. A generalised cost adjustment is carried out, and a new iteration is performed resulting in new flows. The stochastic assignment for user equilibrium assumes that users do not have complete information about the attributes of the network and that they perceive cost differently, thereby producing more realistic results.

An intermodal network was considered. In addition to the links representing waterways, links representing roads were included. Roads are essential for accessing ports. The network was modelled using the TransCAD ${ }^{\circledast}$ software (Caliper Corporation 2016), based on the strategic model proposed by Cantillo et al. (2014). Figure 6 shows the flows per day across the network. Only the navigable inland waterways are marked with the colour scale. Links representing roads are fixed in black. The routes with higher flows are in red, and the routes gradually fade to green for smaller flows.

Additionally, Table 5 shows the minimum and maximum values of different trip characteristics. In the table, it is possible to see how much variation exists in each variable and it provides a point of reference to compare this investigation with future models. 


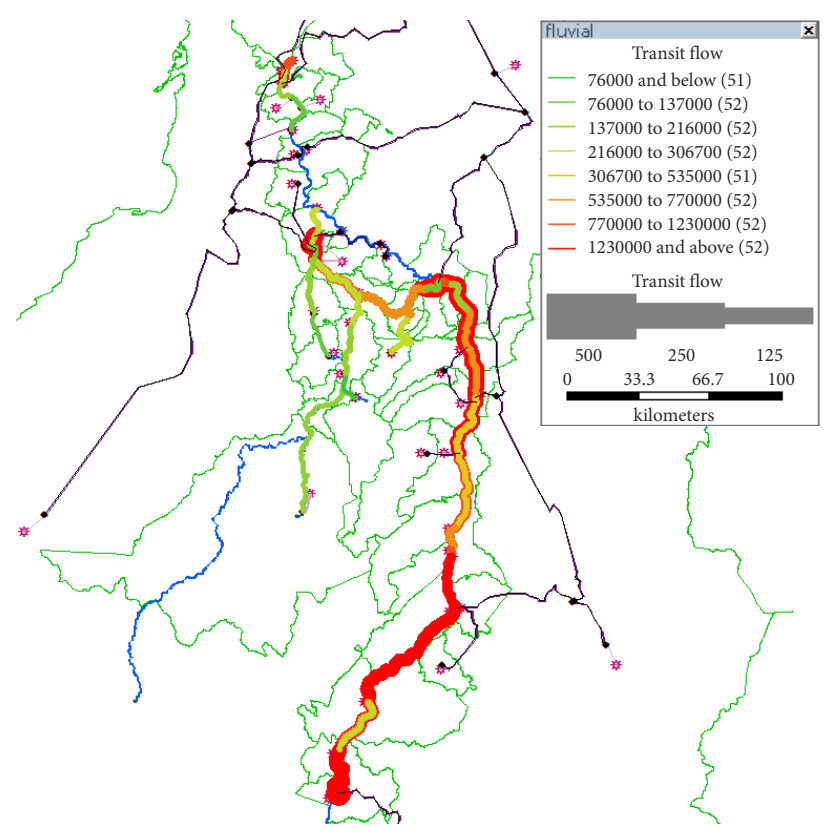

Figure 6. Flow assignment

Table 5. Minimum and maximum values of trip variables

\begin{tabular}{|l|c|c|}
\hline \multicolumn{1}{|c|}{ Trip characteristic } & Minimum & Maximum \\
\hline Generalised cost [thousands COP] & 5.6 & 1206.7 \\
\hline Fare [thousands COP] & 1.0 & 511.2 \\
\hline Time in vehicle [min] & 1.4 & 1474.2 \\
\hline Initial waiting time [min] & 10.0 & 194.2 \\
\hline Transfer waiting time [min] & 0.0 & 550.5 \\
\hline Travel time in Chalupa [min] & 6.6 & 1181.1 \\
\hline Travel time in Motocanoa [min] & 5.3 & 541.5 \\
\hline Travel time in Ferry [min] & 5.3 & 13.8 \\
\hline
\end{tabular}

\section{Policy implications}

The Ministry of Transport supported this research. The models were used to design and evaluate the impact of policies designed to improve the level of service and to stimulate the use of inland waterway transport.

According to the models, the fare and travel time are the most influential variables on demand. In other words, as expected, the generalised cost is a key variable for increasing inland waterway passengers. Nevertheless, there are other variables to be considered to make inland waterway passenger transport more attractive.

Currently, there are no subsidies for inland waterway transport, so a policy to consider is to establish subsidies for integrated transport services in which the main mode is the river. This policy would have high impact, taking into account that their users are low-income persons.

Accessibility is also a significant variable. In consequence, it is possible to catch more trips by improving network connections that make the inland waterway transport mode more accessible to distant areas. Likewise, the presence of river inspections are, as well, a proxy for greater demand. The presence of inspections also means more organised services and even better customer service. A good policy, then, would be to improve the services in smaller municipalities; for example, creating information points, specific stops with suitable infrastructure, or trip schedules.

Designing an integrated system in which the river is a trunk service fed by road or by minor inland waterway services will improve the level of service. Considering that the Magdalena River's area of influence has an incipient infrastructure, consideration has been given to using small vehicles as feeders (e.g. rickshaws, utility cars, and vans). The strategic model was used to model different scenarios of integrated services, whereby encouraging indicators were obtained. The results show decreases in generalised travel costs in the range of 5 to $15 \%$ for inland waterway users.

In the same way, because the frequency was an important variable in the mode choice model and the direct demand model, a logical policy is to offer additional services between zones. Also, creating a designated schedule and informing the user about it in such a way that users perceive the frequency as it really is. Since the country has achieved broad coverage in access to the Internet and mobile networks, the design of apps (trip planners) providing information on the routes, schedules, and frequencies of river transport services will help reduce uncertainties and improve the level of service.

The relevance of variables like frequency and number of transfers give a clear idea of the quantitative aspects that could be changed; however, considering the reduced time value obtained, it is possible to relate those variables to qualitative ones that were not measured (e.g. comfort and security). To understand the importance users give to such variables, more research is needed.

Regarding the assignment model, current and future services are enough to supply the expected demand. However, the service could be improved by optimising the routes, creating express routes and multimodal transport services to allow distant areas to access inland waterway transport easily. For example, one common route used is Barranquilla to Magangué (by road) and Magangué to Mompox (by river). The former route is a multimodal service that begins in Barranquilla and makes a planned transfer in Magangué. Therefore, reducing transfer time and improving the organisational system would be more attractive for travellers.

\section{Conclusions}

This paper contributes to closing a gap in the state of the art and the practice regarding the planning of inland waterway transport for passengers, which is rarely found in the literature. For representing the behaviour of inland waterway transport passengers, this article evaluates two alternative modelling approaches. The four-step classic transport modelling approach is first adapted to inland waterways used for passenger transport. Secondly, alter- 
native synthetic demand models were also estimated. The models were applied to study the passenger mobility on the Magdalena River, the most important waterway in Colombia.

Even though estimation results for both methods were consistent, adapting traditional four-step approaches for modelling inland waterway passenger transport is recommended. Traditional modelling allows for a better understanding of travel behaviour decisions; also, they incorporate the competition between different transport modes and the influence of transport-related variables such as accessibility. However, due to the need for more detailed information for traditional modelling, synthetic approaches are useful when data is rather limited.

Relevant methodological contributions in this paper include the use of the accessibility variable in generation models, the use of mixed stated and RP data for modal split models, and the estimation of relevant indicators, such as the subjective value of time and elasticities to variables in the analysed context. Although the results of this paper may be specific to Colombia, the methodological approach may be adapted to other contexts.

According to the theoretical expectations, the number of generated and attracted trips using the waterway in each area is proportional to the population size. However, this conclusion only fits the influential zone of the river because, in those areas where the waterway mode does not represent a feasible transport alternative, trips are only generated or attracted if the waterway transport is used on a leg of a journey to reach the destination. That is why accessibility also proved to be a relevant variable for trip generation and attraction.

In the zones where river inspections occur, and even in nearby areas, the number of trips is higher. The presence of such an institution is an accessibility indicator and also a factor of organisation and formality in the provision of the service. In addition to the variables mentioned above, others variables regarding economic activities and socioeconomics were also evaluated, but they were not significant for the model.

The mode choice analysis mixed RP and SP data. Using hypothetical scenarios, passengers were forced to choose between road, rail, and waterway transport services. The models suggest that the inland waterway is more sensitive than the road (bus) and the rail mode regarding changes in price and travel time. The former finding implies that improving the waterway passenger transport will create more impact than those improvements made in the other modes. Additionally, demand is more sensitive to cost than to travel time and headway. This means that to stimulate waterway transport, it is necessary to reduce cost over travel time or increased frequency. In this context, a policy to be considered is to subsidise inland waterways passenger transport services.

To account for the travel behaviour of users in the direct demand modelling, a generalised cost function considering travel time and fare was used. In addition to the generalised cost, the synthetic model also considers population and transport-related variables such as transfers and the frequency of the service. The estimation results of this model point out that the demand elasticity of the generalised cost is the highest, which is in line with the result obtained by applying the classical approach. Also, the model considers the number of transfers that are necessary to complete a trip. The number of transfers was significant and very elastic, which suggests that creating direct travel services would increase the demand.

The model was used to evaluate policies oriented towards improving the service level. In particular, the design of integrated services (trunk-feeders), using the Magdalena River as a trunk. The results are promising given that savings would be achieved by users in the range from 5 to $15 \%$ of their generalised travel costs.

In this study, no demand analysis discriminating for travel purpose or income level was conducted. Future research may be focused on these variables. An important application of the estimated models is to define planning scenarios evaluating policies and interventions in the network; particularly level of service improvements in both waterways and roads, or the introduction of new navigable, inland options in the network. Another line of research may also be focused towards the estimation of models involving users' perceptions regarding the comfort and safety of the service.

\section{Funding}

This research was supported by Findeter and the Colombian General Royalties System through the project Diamante Caribe y Santanderes (Cod. 2014000100012).

\section{Disclosure statement}

The author declare that we do not have any competing financial, professional, or personal interests from other parties.

\section{References}

Ben-Akiva, M.; Morikawa, T. 1990. Estimation of travel demand models from multiple data sources, in Transportation and Traffic Theory: Proceedings of the Eleventh International Symposium, 18-20 July, 1990, Yokohama, Japan, 461-476.

Caliper Corporation. 2016. Travel demand modeling with TransCAD: Transportation Planning Software. 24 p. Available from Internet: https://www.caliper.com/pdfs/TravelDemandModelingBrochure.pdf

Camay, S.; Zielinski, E.; Zaranko, A. 2012. New York City's east river ferry: expanding passenger ferry service and stimulating economic development in the New York City Region, Transportation Research Record: Journal of the Transportation Research Board 2274: 192-200. https://doi.org/10.3141/2274-21

Cantillo, V.; Holguín-Veras, J.; Jaller, M. 2014. The Colombian strategic freight transport model based on product analysis, Promet - Traffic \& Transportation 26(6): 487-496.

https://doi.org/10.7307/ptt.v26i6.1460 
Cascetta, E.; Pagliara, F.; Papola, A. 2007. Alternative approaches to trip distribution modelling: a retrospective review and suggestions for combining different approaches, Regional Science 86(4): 597-620.

https://doi.org/10.1111/j.1435-5957.2007.00135.x

Dobbins, J. P.; Langsdon, L. C. 2013. Use of data from automatic identification systems to generate inland waterway trip information, Transportation Research Record: Journal of the Transportation Research Board 2330: 73-79. https://doi.org/10.3141/2330-10

Domencich, T.; McFadden, D. L. 1975. Urban Travel Demand: a Behavioral Analysis. North-Holland Publishing Co. 215 p.

Dong, X.; Ben-Akiva, M.; Bowman, J. L.; Walker, J. L. 2006. Moving from trip-based to activity-based measures of accessibility, Transportation Research Part A: Policy and Practice 40(2): 163-180. https://doi.org/10.1016/j.tra.2005.05.002

Hyman, G. M. 1969. The calibration of trip distribution models, Environment and Planning A: Economy and Space 1(1): 105-112. https://doi.org/10.1068/a010105

Ivančić, P.; Kasum, J.; Pavić, I. 2013. Proposed guidelines on developing the optimisation model for passage planning in inland waterways navigation, Pomorstvo - Scientific Journal of Maritime Research 27(2): 343-350.

Kim, J. H.; Bae, Y. K.; Chung, J.-H. 2012. Effects of personal proenvironmental attitudes on mode choice behavior: new ecofriendly water transit system in Seoul, South Korea, Transportation Research Record: Journal of the Transportation Research Board 2274: 175-183. https://doi.org/10.3141/2274-19

Márquez, L.; Cantillo, V.; Arellana, J. 2014. How are comfort and safety perceived by inland waterway transport passengers?, Transport Policy 36: 46-52.

https://doi.org/10.1016/j.tranpol.2014.07.006

Márquez, L.; Cantillo, V. 2013. Evaluating strategic freight transport corridors including external costs, Transportation Planning and Technology 36(6): 529-546. https://doi.org/10.1080/03081060.2013.830892

Mihic, S.; Golusin, M.; Mihajlovic, M. 2011. Policy and promotion of sustainable inland waterway transport in Europe Danube River, Renewable and Sustainable Energy Reviews 15(4): 1801-1809. https://doi.org/10.1016/j.rser.2010.11.033

Nam, K.; Win, E. 2014. Competitiveness between road and inland water transport: the case of Myanmar, Transport Problems - Problemy Transportu 9(4): 49-61.

Ortúzar, J. de D.; Willumsen, L. G. 2011. Modelling Transport. John Wiley \& Sons, Ltd. 607 p. https://doi.org/10.1002/9781119993308

Sheffi, Y. 1985. Urban Transportation Networks: Equilibrium Analysis with Mathematical Programming Methods. Prentice Hall. 399 p.

Tournaye, C.; Pauli, G.; Saha, D. M.; Van der Werf, H. 2010. Current issues of inland water transport in Europe, Proceedings of the Institution of Civil Engineers - Civil Engineering 163(5): 19-28. https://doi.org/10.1680/cien.2010.163.5.19

Vega, L.; Cantillo, V.; Arellana, J. 2019. Assessing the impact of major infrastructure projects on port choice decision: the Colombian case, Transportation Research Part A: Policy and Practice 120: 132-148. https://doi.org/10.1016/j.tra.2018.12.021

Wardman, M.; Lythgoe, W.; Whelan, G. 2007. Rail passenger demand forecasting: cross-sectional models revisited, Research in Transportation Economics 20: 119-152. https://doi.org/10.1016/S0739-8859(07)20005-8 